REPUBLICA DE COLOMBIA

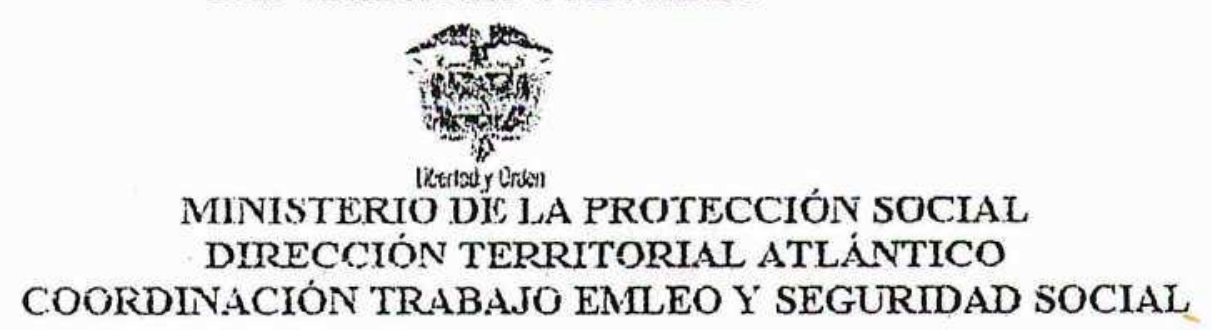

RESOLUCIÓN

60072

14.00 .2006

"Por la cual se aprueba un Reglamento Interno de Trabajo"

LA COORDINADORA DEL GRUPO TRABAJO, EMPLEO Y SEGURIDAD SDCIAL DEL ATLANTICO, EN USO DE LAS FACULTADES LEGALES CONFERIDAS POR EL DECRETO 01 DE 1984, ARTICULOS 104 A 125 DEL CÓDIGO SUSTANTIVO DEL TRABAJO, RESOLUCIÓN 000951 DEL 28 DE ABRII. 2003, Y

\title{
CONSIDERANDO
}

Que el señor TITO JOSE CRISSIEN BORRERO, Representante Legal de la CORPORACION UNIVERSITARIA DE LA COSTA "CUC", con domicilio en la ciudad de Barranquilla, medianta documentación radicada bajo No. 4873 del 08 de Agosto de 2006, solicito la aprobación del proyecto de reglamento interno de trabajo prescrito para el mencionado ente y sus trabajadores.

Realizado el estudio de los documentos presentados, se observ6 que el proyecto de Regianitiento interno de Trabajo del citado empieador, reúne los requisitos exigidos por el articulo 108 del Código Sustantivo de Trabajo y demás normas vigentes sobre la materia, para su aprobación.

Que do acuerdo a las disposiciones legales, correspondo a éste Despacho aprobar los reglamentos internos de trabajo presentados por los empleadores domiciliados en la jurisdicción de la Coordinación de Trabajo, Empleo y Seguridad Social de la Dirección Territorial de Trabajo y Seguridad Social del Atlántico.

A merito de io anterior

RESUELVE

ARTícULO $1^{\circ}$.- Aprobar el Reglamento Interno de Trabajo prescrito por la CORPORACIÓN UIVIVERSITARIA DE LA COSTA “CUC”. 


\title{
REPUBLICA DE COLOMBIA
}

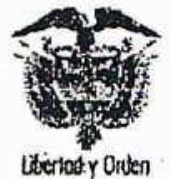 \\ MINISTERIO DE LA PROTECCIÓN SOCIAL \\ DIRECCIÓN TERRITORIAL ATLÁNTICO \\ COORDINACIÓN TRABAJO EMLEO Y SEGURIDAD SOCIAL
}

ARTICULO $2^{\circ}$.- Dentro de los quince (15) días siguientes al de la notificación de la presente resolución, el empleador debe publicar el reglamento interno de trabajo aprobado en el lugar de trabajo, mediante la fijación de dos (2) copias on caracteres legiblos, on dos (2) sitios distintos. Si hubiere varios lugares de trabajo separados, la fijación debe hacerse en cada uno de ellos. Con el reglamento debe publicarse la resolución aprobatoria.

ARTICULO $3^{\circ}$.- Contra la presente providencla procede el recurso de reposición ante el Despacho que la profirio y el de apelación para ante el Director Territorial de Trabajo y Seguridad Social del Atlántico, interpuestos por escrito, en la diligencia de notificación persotnal, o dentro de los cinco (5) dias hábiles siguientes a ella, o a la desfijación del edicto según el caso.

ARTICULO $4^{\circ}$.- Notificar a los juridicamente interesados en los términos establecidos por el Decreto 01 de 1984.

Dada en Barranquilla, a los

$$
\text { 12. } 600.2006
$$

NOTIFIQUESE Y CÚMPLASE

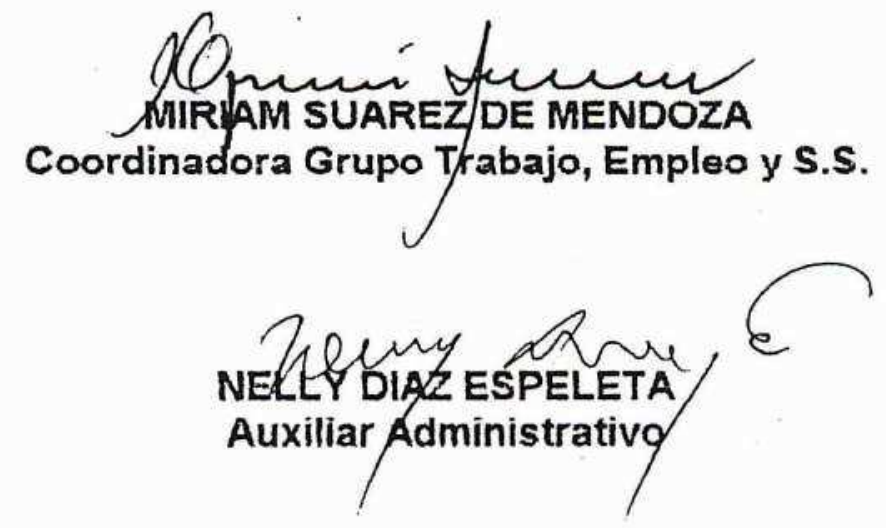




\section{REGLAMENTO INTERNO DE TRABAJO}

\section{CAPITULO I}

ARTICULO $1^{\circ}$-El presente reglamento interno de trabajo actualizado con las normas laborales vigentes que se transcribe por la CORPORACIÓN UNIVERSITARIA DE LA COSTA, CUC entidad de carácter civil, sin animo de lucro domiciliada en Barranquilla, con Personería Jurídica reconocida por la Gobernación del Atlántico, mediante Resolución No. 352 del 23 de Abril de 1971 y a sus disposiciones quedan sometidas tanto la empresa como todos sus trabajadores. Este reglamento hace parte de los contratos individuales de trabajo, celebrados o que se celebren con todos los trabajadores, salvo estipulaciones en contrario que sin embargo sólo pueden ser favorables al trabajador.

\section{CAPITULO II}

\section{CONDICIONES DE ADMISIÓN}

ARTICULO $2^{\circ}-$ Quien aspire al ingreso como trabajador de la CORPORACIÓN UNIVERSITARIA DE LA COSTA debe hacer la solicitud por escrito para registrarlo como aspirante y acompañar los siguientes documentos:

a) Cédula de ciudadanía o tarjeta de identidad según el caso;

b) Autorización escrita del inspector del trabajo o, en su defecto, de la primera autoridad local, a solicitud de los padres y, a falta de éstos, del defensor de familia, cuando el aspirante sea un menor de dieciocho (18) años;

c) Si se trata de profesionales o tecnólogos deben adjuntar fotocopias de sus respectivos diplomas y actas de grado.

d) Certificado del ultimo empleador con quien haya trabajado, en el cual conste el tiempo de servicio, la indole de la labor ejecutada y el salario devengado.

e) Registro civil de nacimiento.

f) Certificado de personas honorables sobre su conducta y capacidad.

Los menores de dieciocho (18) años de edad necesitan para celebrar contrato de trabajo, autorización escrita del inspector del Ministerio de la Protección Social o de la primera autoridad política del lugar, previo consentimiento de sus representantes legales.

Concedida la autorización el menor de dieciocho (18) años puede percibir directamente el salario y llegado el caso, ejercitar las acciones legales pertinentes.

\section{CAPITULO III}

\section{CONTRATO DE APRENDIZAJE}

ARTÍCULO $3^{\circ}$-Naturaleza y caracteristicas de la relación de aprendizaje. El contrato de aprendizaje es una forma especial dentro del Derecho Laboral, mediante la cual una persona natural desarrolla formación teórica práctica en una entidad autorizada, a cambio de que una empresa patrocinadora proporcione los medios para adquirir formación profesional metódica y completa requerida en el oficio, actividad u ocupación y esto le implique desempeñarse dentro del manejo administrativo, operativo comercial o financiero propios del giro ordinario de las actividades de la empresa, por cualquier tiempo determinado no superior a dos (2) años, y por esto reciba un apoyo de sostenimiento mensual, el cual en ningún caso constituye salario.

Son elementos particulares y especiales del contrato de aprendizaje:

a) La finalidad es la de facilitar la formación de las ocupaciones en las que se refiere el presente artículo;

b) La subordinación está referida exclusivamente a las actividades propias del aprendizaje;

c) La formación se recibe a título estrictamente personal;

d) El apoyo del sostenimiento mensual tiene como fin garantizar el proceso de aprendizaje.

Durante toda la vigencia de la relación, el aprendiz recibirá de la empresa un apoyo de sostenimiento mensual que sea como mínimo en la fase lectiva el equivalente al $50 \%$ de un (1) salario mínimo mensual vigente.

El apoyo del sostenimiento durante la fase práctica será equivalente al setenta y cinco por ciento $(75 \%)$ de un salario mínimo mensual legal vigente.

El apoyo de sostenimiento durante la fase práctica será diferente cuando la tasa de desempleo nacional sea menor del diez por ciento $(10 \%)$, caso en el cual será equivalente al ciento por ciento (100\%) de un salario minimo legal vigente.

En ningún caso el apoyo de sostenimiento mensual podrá ser regulado a través de convenios o contratos colectivos o fallos arbítrales recaidos en una negociación colectiva.

Si el aprendiz es estudiante universitario el apoyo mensual, el apoyo de sostenimiento mensual no podrá ser inferior al equivalente a un salario minimo legal vigente. 
Durante la fase práctica el aprendiz estará afiliado en riesgos profesionales por la ARP que cubre la empresa. En materia de salud, durante las fases lectiva y práctica, el aprendiz estará cubierto por el Sistema de Seguridad Social en Salud, conforme al régimen de trabajadores independientes, y pagado plenamente por la empresa patrocinadora en los términos, condiciones y beneficios que defina el Gobierno Nacional.

El contrato de aprendizaje podrá versar sobre ocupaciones semicalificadas que no requieran título o calificadas que requieran título de formación técnica no formal, técnicos profesionales o tecnológicos, de instituciones de educación reconocidas por el Estado y trabajadores aprendices del SENA.

El Contrato de aprendizaje podrá versar sobre estudiantes universitarios para los casos en que el aprendiz cumpla con actividades de 24 horas semanales en la empresa y al mismo tiempo cumpla con el desarrollo del pénsum de su carrera profesional, o que curse el semestre de práctica. En todo caso la actividad del aprendiz deberá guardar relación con su formación académica.

ARTICULO $4^{\circ}$ - Modalidades especiales de formación técnica, tecnológica, profesional y teórico práctica empresarial. Además de lo dispuesto en el artículo anterior, se consideran modalidades de contrato de aprendizaje las siguientes:

a) Las prácticas con estudiantes universitarios, técnicos o tecnólogos que las empresas establezcan directamente o con instituciones de educación aprobadas por el Estado, de conformidad con las Leyes 30 de 1992 y 115 de 1994 o normas que la adicionen, modifiquen o sustituyan, que establezcan dentro de su programa curricular este tipo de prácticas para afianzar los conocimientos teóricos. En estos casos no habrá lugar a brindar formación académica, circunscribiéndose la relación al otorgamiento de experiencia y formación práctica empresarial. El número de prácticas con estudiantes universitarios debe tratarse de personal adicional comprobable con respecto al número de empleados registrados en el último mes del año anterior en las Cajas de Compensación;

b) La realizada en las empresas por jóvenes que se encuentren cursando los dos últimos grados de educación lectiva secundaria en instituciones aprobadas por el Estado;

c) El aprendiz alumno matriculado en los cursos dictados por Servicio Nacional de Aprendizaje, SENA, de acuerdo con el artículo $5^{\circ}$ del Decreto 2838 de 1960 ;

d) El aprendiz de capacitación de nivel semicalificado. Se entiende como nivel de capacitación semicalificado, la capacitación teórica y práctica que se oriente a formar para desempeños en los cuales predominan procedimientos claramente definidos a partir de instrucciones específicas (por ejemplo auxiliares de mecánica, auxiliares de cocina, auxiliares de electricista, plomería, etc.). Para acceder a este nivel de capacitación, las exigencias de educación formal y experiencia son minimas. Este nivel de capacitación es específicamente relevante para jóvenes de los estratos más pobres de la población que carecen de, o tienen bajos niveles de educación formal y experiencia.

Parágrafo. En ningún caso los apoyos de sostenimiento mensual de que trata la presente ley podrán ser regulados a través de convenios o contratos colectivos o fallos arbítrales recaídos en una negociación colectiva.

ARTICULO $5^{\circ}$ - Empresas obligadas a la vinculación de aprendices. Las empresas privadas, desarrolladas por personas naturales o jurídicas, que realicen cualquier tipo de actividad económica diferente de la construcción, que ocupen un número de trabajadores no inferior a quince (15), se encuentran obligadas a vincular aprendices para los oficios u ocupaciones que requieran formación académica o profesional metódica y completa en la actividad económica que desempeñan.

Las empresas industriales y comerciales del Estado y las de Economía mixta del orden Nacional, departamental, distrital y municipal, estarán obligadas a la vinculación de aprendices en los términos de esta ley. Las demás entidades públicas no estarán sometidas a la cuota de aprendizaje, salvo en los casos que determine el Gobierno Nacional.

El empresario obligado a cumplir con la cuota de aprendizaje podrá tener practicantes universitarios bajo la modalidad de relación de aprendizaje, en el desarrollo de actividades propias de la empresa, siempre y cuando estos no superen el $25 \%$ del total de aprendices.

Parágrafo. Empresas de menos de diez (10) trabajadores podrán voluntariamente tener un aprendiz de formación del SENA.

ARTICULO $6^{\circ}$ - Cuotas de aprendices en las empresas. La determinación del número mínimo obligatorio de aprendices para cada empresa obligada la hará la regional del Servicio Nacional de Aprendizaje, SENA, del domicilio principal de la empresa, en razón de un aprendiz por cada 20 trabajadores y uno adicional por fracción de diez (10) o superior que no exceda de veinte. Las Empresas que tengan entre quince (15) y veinte (20) trabajadores, tendrán un aprendiz.

ARTICULO $7^{\circ}$ - Monetización de la cuota de aprendizaje. Los obligados a cumplir la cuota de aprendizaje de acuerdo con los artículos anteriores podrán en su defecto cancelar al SENA una cuota mensual resultante de multiplicar el $5 \%$ del número total de trabajadores, excluyendo los trabajadores independientes o transitorios, por un salario mínimo legal vigente. En caso que la monetización sea parcial esta será proporcional al número de aprendices que dejen de hacer la práctica para cumplir la cuota mínima obligatoria.

ARTÍCULO $8^{\circ}$ - Selección de aprendices. La empresa obligada a la vinculación de aprendices, será la encargada de seleccionar los oficios u ocupaciones objeto de este contrato de aprendizaje así como las modalidades y los postulantes para los mismos, de acuerdo con los perfiles y requerimientos concretos de mano de obra calificada y semicalificada así como de la disponibilidad de personal que tenga para atender oficios u ocupaciones similares. La empresa podrá acudir a los listados de preselección de aprendices elaborados por el SENA, priorizando la formación semicalificada, técnica o tecnológica. 
Parágrafo. Las empresas no podrán contratar bajo la modalidad de aprendices a personas que hayan estado o se encuentren vinculadas laboralmente a la misma.

ARTICULO $9^{\circ}$ - Listado de oficios materia del contrato de aprendizaje. Podrán ser objeto del contrato de aprendizaje en cualquiera de sus modalidades, todos los oficios u ocupaciones que requieran de capacitación académica integral y completa para su ejercicio y se encuentren reconocidos como propios de formación educativa técnica profesional, tecnológica o profesional universitaria titulada, de conformidad con los parámetros generales establecidos por las Leyes 30 de 1992 y 115 de 1994 o normas que las sustituyan, modifiquen, adicionen, reglamenten o regulen de manera específica estas materias.

La etapa lectiva o de formación profesional integral de tales oficios podrá ser realizada en el SENA, en instituciones educativas o especializadas reconocidas por el Estado, o directamente en la empresa previa autorización del SENA, de conformidad con lo establecido por la presente reglamentación.

ARTÍCULO $10^{\circ}$ - Entidades de formación. La formación profesional y metódica de aprendices podrá ser impartida por las siguientes entidades:

a) Servicio Nacional de Aprendizaje, SENA.

b) Instituciones educativas debidamente reconocidas por el Estado. Se le dará prelación al SENA en los programas acreditados que brinde la entidad.

c) Directamente por las empresas que cumplan con las condiciones de capacitación señaladas en el artículo 41 de la ley 789 de 2002.

d) Las demás que sean objeto de reglamentación por parte del Consejo Directivo del SENA.

Parágrafo. Para los efectos legales, se entienden reconocidos por el SENA para la formación profesional de aprendices, todos los cursos y programas de formación y capacitación dictados por establecimientos especializados o instituciones educativas reconocidos por el Estado, de conformidad con las Leyes 30/92 y 115/94 y demás que las complementen, modifiquen o adicionen.

ARTICULO $11^{\circ}$ - Reconocimiento para efectos de la formación profesional impartida directamente por la empresa. Las empresas que deseen impartir directamente la formación educativa a sus aprendices requerirán de autorización del SENA para dictar los respectivos cursos, para lo cual deberán cumplir las siguientes condiciones:

a) Ofrecer un contenido de formación lectiva y práctica acorde con las necesidades de la formación profesional integral y del mercado de trabajo.

b) Disponer de recursos humanos calificados en las áreas en que ejecuten los programas de formación profesional integral.

c) Garantizar, directamente o a través de convenios con terceros, los recursos técnicos, pedagógicos y administrativos que garanticen su adecuada implementación.

Parágrafo. La empresa al recibir autorización por parte del SENA para impartir la formación educativa, solicitará el reembolso económico del costo de la formación, cuyo monto será definido por el SENA tomando en consideración los costos equivalentes en que incurre el SENA en cursos de formación similares. En ningún caso el monto reembolsable al año por empresa podrá superar el $50 \%$ del valor de los aportes parafiscales al SENA de la respectiva empresa.

ARTICULO $12^{\circ}-$ Distribución y alternancia de tiempo entre la etapa lectiva y productiva. La empresa y la entidạd de formación podrán determinar la duración de la etapa productiva, al igual que su alternancia con la lectiva, de acuerdo con las necesidades de la formación del aprendiz y los requerimientos de la empresa. Para los técnicos o tecnólogos será de un (1) año.

En el caso de cursos y programas impartidos por otras instituciones aprobadas por el Estado, el término máximo de formación lectiva será la exigida por la respectiva entidad educativa, de acuerdo con lo señalado por el Ministerio de Educación, para optar por el respectivo grado académico y/o técnico.

Los tiempos máximos que se fijen para la etapa de formación en la empresa autorizada, en ningún caso podrán ser superiores a los contemplados en la etapa de formación del SENA.

\section{CAPITULO IV}

\section{PERÍODO DE PRUEBA}

ARTICULO $13^{\circ}$ - La empresa una vez admitido el aspirante podrá estipular con el período inicial de prueba que tendrá por objeto apreciar por parte de la empresa, las aptitudes del trabajador y por parte de éste, las conveniencias de las condiciones de trabajo (CST, art. 76).

ARTICULO $14^{\circ}-\mathrm{El}$ periodo de prueba debe ser estipulado por escrito y en caso contrario los servicios se entienden regulados por las normas generales del contrato de trabajo (CST, art. 77 , num. $1^{\circ}$ ). 
ARTICULO $15^{\circ}-$ El periodo de prueba no puede exceder de dos (2) meses. En los contratos de trabajo a término fijo, cuya duración sea inferior a un (1) año, el período de prueba no podrá ser superior a la quinta parte del término inicialmente pactado para el respectivo contrato, sin que pueda exceder de dos meses.

Cuando entre un mismo empleador y trabajador se celebren contratos de trabajo sucesivos, no es válida la estipulación del periodo de prueba, salvo para el primer contrato (L. 50/90, art. $7^{\circ}$ ).

ARTICULO $16^{\circ}$-Durante el periodo de prueba, el contrato puede darse por terminado unilateralmente en cualquier momento y sin previo aviso, pero si expirado el periodo de prueba y el trabajador continuare al servicio del empleador, con consentimiento expreso o tácito, por ese solo hecho, los servicios prestados por aquél a éste, se considerarán regulados por las normas del contrato de trabajo desde la iniciación de dicho período de prueba. Los trabajadores en periodo de prueba gozan de todas las prestaciones (CST, art. 80).

\title{
CAPÍTULO V
}

\section{TRABAJADORES ACCIDENTALES O TRANSITORIOS}

ARTICULO $17^{\circ}$-Son meros trabajadores accidentales o transitorios, los que se ocupen en labores de corta duración no mayor de un mes y de indole distinta a las actividades normales de la empresa. Estos trabajadores tienen derecho, además del salario, al descanso remunerado en dominicales y festivos (CST, art. $\left.6^{\circ}\right)$.

\section{CAPÍtULO VI}

\section{HORARIO DE TRABAJO}

ARTICULO $18^{\circ}$ - Las horas de entrada y salida de los trabajadores son las que a continuación se expresan así:

\author{
DÍAS LABORABLES \\ Oficinas Administrativas: \\ En la mañana: De 7:30 A.M. a $12.00 \mathrm{M}$ \\ En la tarde: De 2.00 P.M. a 6.30 P.M. \\ Sábados: Dpto. de Biblioteca de: 8.00 A.M. a 12.00 M. \\ Departamento de Mantenimiento y Servicios Generales \\ En la mañana: De 7:00 A.M. a $12.00 \mathrm{M}$ \\ En la tarde: $\quad$ De $\quad 1.00$ P.M. a 5.00 P.M. \\ Sábados: 8.00 A.M. a 12.00 M.
}

PARAGRAFO $1^{\circ}$-Cuando la empresa tenga más de cincuenta (50) trabajadores que laboren cuarenta y ocho (48) horas a la semana, éstos tendrán derecho a que dos (2) horas de dicha jornada, por cuenta del empleador, se dediquen exclusivamente a actividades recreativas, culturales, deportivas o de capacitación (L. 50/90, art. 21).

PARAGRAFO $2^{\circ}$-Del horario anterior quedan exceptuados: Jornada especial. En las empresas, factorias o nuevas actividades establecidas desde el primero de enero de 1991, el empleador y los trabajadores pueden acordar temporal o indefinidamente la organización de turnos de trabajo sucesivos, que permitan operar a la empresa o secciones de la misma sin solución de continuidad durante todos los dias de la semana, siempre y cuando el respectivo turno no exceda de seis horas al día y treinta y seis (36) a la semana.

En este caso no habrá lugar al recargo nocturno ni al previsto para el trabajo dominical o festivo, pero el trabajador devengará el salario correspondiente a la jornada ordinaria de trabajo, respetando siempre el mínimo legal o convencional y tendrá derecho a un (1) día de descanso remunerado.

El empleador no podrá, aun con el consentimiento del trabajador, contratarlo para la ejecución de dos (2) turnos en el mismo día, salvo en labores de supervisión, dirección, confianza o manejo (L. 50/90, art. 20, lit. c)

ARTICULO $19^{\circ}$ - Cuando por fuerza mayor o caso fortuito que determine suspensión del trabajo por tiempo no mayor de dos (2) horas no pueda desarrollarse la jornada de trabajo dentro del horario antedicho, se cumplirá en igual numero de horas distintas a las del horario, sin que el servicio prestado en tales horas constituya trabajo suplementario, ni implique sobre remuneración alguna.

ARTICULO $20^{\circ}$-El número de horas de trabajo señalado en el horario anterior podrá ser elevado por orden del empleador sin permiso de autoridad, por razón de fuerza mayor en caso de amenaza o en caso de amenaza de accidente que determinen la ejecución de trabajos 
de urgencia que deban efectuarse en los equipos o en las instalaciones del empleador, pero solo en la medida que sea necesario para evitar que la marcha normal de la institución sufra una perturbación grave. Esta ampliación constituye trabajo suplementario o de horas extras.

ARTICULO $21^{\circ}$ - También podrá el empleador ampliar la jornada ordinaria en aquellos casos en que por razón de su misma naturaleza, necesitan ser atendidos sin solución de continuidad, por turnos sucesivos de trabajo, pero en tales casos las horas de trabajo no podrán exceder de cincuenta y seis (56) en los días hábiles de la semana.

\section{CAPÍTULO VII}

\section{HORAS EXTRAS Y TRABAJO NOCTURNO}

ARTICULO $22^{\circ}$-Trabajo diurno es el comprendido entre las 6:00 a.m. y las 10:00 p.m. y el trabajo nocturno es el comprendido entre las 10:00 p.m. y las 6:00 a.m.

ARTICULO $23^{\circ}$ - Trabajo suplementario o de horas extras es el que se excede de la jornada ordinaria y en todo caso el que excede la máxima legal (CST, art. 159).

ARTICULO $24^{\circ}$-El trabajo suplementario o de horas extras, a excepción de los casos señalados en el artículo 163 del Código Sustantivo del Trabajo, sólo podrá efectuarse en dos (2) horas diarias y mediante autorización expresa del Ministerio de la Protección Social o de una autoridad delegada por éste (D. $13 / 67$, art. $1^{\circ}$ ).

ARTÍCULO $25^{\circ}$-Tasas y liquidación de recargos.

a) El trabajo nocturno, por el solo hecho de ser nocturno se remunera con un recargo del treinta y cinco por ciento (35\%) sobre el valor del trabajo diurno, con excepción del caso de la jornada de treinta y seis (36) horas semanales prevista en el artículo 20 literal c) de la Ley 50 de 1990.

b) El trabajo extra diurno se remunera con un recargo del veinticinco por ciento $(25 \%)$ sobre el valor del trabajo ordinario diurno.

c) El trabajo extra nocturno se remunera con un recargo del setenta y cinco por ciento (75\%) sobre el valor del trabajo ordinario diurno.

d) El trabajo en domingos y festivos se remunerará con un recargo del setenta y cinco por ciento (75\%) sobre el valor del trabajo ordinario en proporción a las horas laboradas. Si con el domingo coincide otro día de descanso remunerado solo tendrá derecho el trabajador, si trabaja, al recargo.

e) Cada uno de los recargos antedichos se produce de manera exclusiva, es decir, sin acumularlo con alguno otro (L. 50/90, art. 24). PARAGRAFO. - La empresa podrá implantar turnos especiales de trabajo nocturno, de acuerdo con lo previsto por el Decreto 2352 de 1965.

ARTICULO $26^{\circ}-$ La empresa no reconocerá trabajo suplementario o de horas extras sino cuando expresamente lo autorice a sus trabajadores de acuerdo con lo establecido para tal efecto en el artículo 18 de este reglamento.

PARAGRAFO $1^{\circ}$-En ningún caso las horas extras de trabajo, diurnas o nocturnas, podrán exceder de dos (2) horas diarias y doce (12) semanales.

Cuando la jornada de trabajo se amplie por acuerdo entre empleadores y trabajadores a diez (10) horas diarias, no se podrá en el mismo dia laborar horas extras.

PARAGRAFO $2^{\circ}$-Descanso en el día sábado. Pueden repartirse las cuarenta y ocho (48) horas semanales de trabajo ampliando la jornada ordinaria hasta por dos horas, por acuerdo entre las partes, pero con el fin exclusivo de permitir a los trabajadores el descanso durante todo el sábado, esta ampliación no constituye trabajo suplementario o de horas extras.

ARTICULO $27^{\circ}$-El pagó de las horas extras y de los recargos por trabajos nocturnos, en su caso, se efectuaran junto con el salario del periodo siguiente.

\section{CAPÍTULO VIII}

\section{DÍAS DE DESCANSO LEGALMENTE OBLIGATORIOS}

ARTICULO $28^{\circ}$ - Serán de descanso obligatorio remunerado, los domingos y días de fiesta que sean reconocidos como tales en nuestra legislación laboral. 
a) Todo trabajador, tiene derecho al descanso remunerado en los siguientes días de fiesta de carácter civil o religioso: $1^{\circ}$ de enero, 6 de enero, 19 de marzo, $1^{\circ}$ de mayo, 29 de junio, 20 de julio, 7 de agosto, 15 de agosto, 12 de octubre, $1^{\circ}$ de noviembre, 11 de noviembre, 8 y 25 de diciembre, además de los días jueves y viernes santos, Ascensión del Señor, Corpus Christi y Sagrado Corazón de Jesús.

b) Pero el descanso remunerado del seis de enero, diez y nueve de marzo, veintinueve de junio, quince de agosto, doce de octubre, primero de noviembre, once de noviembre, Ascensión del Señor, Corpus Christi y Sagrado Corazón de Jesús, cuando no caigan en dia lunes se trasladarán al lunes siguiente a dicho día. Cuando las mencionadas festividades caigan en domingo, el descanso remunerado, igualmente se trasladará al lunes.

c) Las prestaciones y derechos que para el trabajador originen el trabajo en los días festivos, se reconocerá en relación al día de descanso remunerado establecido en el inciso anterior (L. 51/83).

PAR. $1^{\circ}$ - Cuando la jornada de trabajo convenida por las partes, en días u horas, no implique la prestación de servicios en todos los días laborables de la semana, el trabajador tendrá derecho a la remuneración del descanso dominical en proporción al tiempo laborado (L. $50 / 90$, art. 26 , num. $5^{\circ}$ ).

Aviso sobre trabajo dominical. Cuando se tratare de trabajos habituales o permanentes en domingo, el empleador debe fijar en lugar público del establecimiento, con anticipación de doce (12) horas lo menos, la relación del personal de trabajadores que por razones del servicio no puede disponer el descanso dominical. En esta relación se incluirán también el día y las horas de descanso compensatorio (CST, art. 185).

ARTICULO $29^{\circ}$-El descanso en los días domingos y los demás días expresados en el artículo 21 de este reglamento, tiene una duración mínima de 24 horas, salvo la excepción consagrada en el literal c) del artículo 20 de la Ley 50 de 1990 (L. 50/90, art. 25).

ARTICULO $30^{\circ}$-Cuando por motivo de fiesta no determinada en la Ley 51 del 22 de diciembre de 1983, la empresa suspendiere el trabajo, está obligada a pagarlo como si se hubiere realizado. No está obligada a pagarlo cuando hubiere mediado convenio expreso para la suspensión o compensación o estuviere prevista en el reglamento, pacto, convención colectiva o fallo arbitral. Este trabajo compensatorio se remunerará sin que se entienda como trabajo suplementario o de horas extras (CST, art. 178).

\section{CAPÍTULO IX}

\section{VACACIONES REMUNERADAS}

ARTICULO $31^{\circ}$ - Los trabajadores que hubieren prestado sus servicios durante un (1) año tienen derecho a quince (15) días hábiles consecutivos de vacaciones remuneradas (CST, art. 186, num. $1^{\circ}$ ).

ARTICULO $32^{\circ}$ - La época de vacaciones debe ser señalada por la empresa a más tardar dentro del año siguiente y ellas deben ser concedidas oficiosamente o a petición del trabajador, sin perjudicar el servicio y la efectividad del descanso.

El empleador tiene que dar a conocer al trabajador con quince (15) dias de anticipación la fecha en que le concederán las vacaciones (CST, art. 187).

ARTICULO $33^{\circ}-\mathrm{Si}$ se presenta interrupción justificada en el disfrute de las vacaciones, el trabajador no pierde el derecho a reanudarlas (CST, art. 188).

ARTICULO $34^{\circ}$-Se prohíbe compensar las vacaciones en dinero, pero el Ministerio de la Protección Social puede autorizar que se pague en dinero hasta la mitad de ellas en casos especiales de perjuicio para la economía nacional o la industria; cuando el contrato termina sin que el trabajador hubiere disfrutado de vacaciones, la compensación de éstas en dinero procederá por un año cumplido de servicios y proporcionalmente por fracción de año. En todo caso para la compensación de vacaciones, se tendrá como base el último salario devengado por el trabajador (CST, art. 189).

ARTICULO $35^{\circ}$ - En todo caso, el trabajador gozará anualmente, por lo menos de seis (6) dias hábiles continuos de vacaciones, los que no son acumulables.

Las partes pueden convenir en acumular los días restantes de vacaciones hasta por dos años. La acumulación puede ser hasta por cuatro (4) años, cuando se trate de trabajadores técnicos, especializados, y de confianza (CST, art. 190).

ARTICULO $36^{\circ}$-Durante el periodo de vacaciones el trabajador recibirá el salario ordinario que esté devengando el día que comience a disfrutar de ellas. En consecuencia, sólo se excluirán para la liquidación de las vacaciones el valor del trabajo en días de descanso obligatorio y el valor del trabajo suplementario o de horas extras. Cuando el salario sea variable, las vacaciones se liquidarán con el promedio de lo devengado por el trabajador en el año inmediatamente anterior a la fecha en que se conceden. 
ARTICULO $37^{\circ}$-Todo empleador llevará un registro de vacaciones en el que se anotará la fecha de ingreso de cada trabajador, fecha en que toma sus vacaciones, en que las termina y la remuneración de las mismas (D. 13/67, art. $5^{\circ}$ ).

\section{CAPÍTULO IX}

\section{PERMISOS}

ARTICULO $38^{\circ}$ - La empresa concederá a sus trabajadores los permisos necesarios para el ejercicio del derecho al sufragio y para el desempeño de cargos oficiales transitorios de forzosa aceptación, en caso de grave calamidad doméstica debidamente comprobada, para concurrir en su caso al servicio médico correspondiente, para desempeñar comisiones sindicales inherentes a la organización y para asistir al entierro de sus compañeros, siempre que avisen con la debida oportunidad a la empresa y a sus representantes y que en los dos últimos casos, el número de los que se ausenten no sea tal, que perjudiquen el funcionamiento del establecimiento. La concesión de los permisos antes dichos estará sujeta a las siguientes condiciones:

a) En caso de grave calamidad doméstica, la oportunidad del aviso puede ser anterior o posterior al hecho que lo constituye o al tiempo de ocurrir éste, según lo permitan las circunstancias.

b) En caso de entierro de compañeros de trabajo, el aviso puede ser hasta con un día de anticipación y el permiso se concederá hasta el $10 \%$ de los trabajadores.

c) En los demás casos (sufragio, desempeño de cargos transitorios de forzosa aceptación y concurrencia al servicio médico correspondiente) el aviso se hará con la anticipación que las circunstancias lo permitan. Salvo convención en contrario y a excepción del caso de concurrencia al servicio médico correspondiente, el tiempo empleado en estos permisos puede descontarse al trabajador o compensarse con tiempo igual de trabajo efectivo en horas distintas a su jornada ordinaria, a opción de la empresa (CST, art. 57, num. $6^{\circ}$ ).

\section{CAPÍTULO XI}

\section{SALARIO MÍNIMO, CONVENCIONAL, LUGAR, DÍAS, HORAS DE PAGOS Y PERÍODOS QUE LO REGULAN}

ARTICULO $39^{\circ}$-Formas y libertad de estipulación:

a) El empleador y el trabajador pueden convenir libremente el salario en sus diversas modalidades como por unidad de tiempo, por obra, o a destajo y por tarea, etc., pero siempre respetando el salario mínimo legal o el fijado en los pactos, convenciones colectivas y fallos arbítrales, en caso de existir estos actos.

b) No obstante lo dispuesto en los artículos 13,14,16,21 y 340 del Código Sustantivo del Trabajo y las normas concordantes con éstas, cuando el trabajador devengue un salario ordinario superior a diez (10) salarios mínimos legales mensuales, valdrá la estipulación escrita de un salario que además de retribuir el trabajo ordinario, compense de antemano el valor de prestaciones, recargos y beneficios tales como el correspondiente al trabajo nocturno, extraordinario o al dominical y festivo, el de primas legales, extralegales, las cesantías y sus intereses, subsidios y suministros en especie; y, en general, las que se incluyan en dicha estipulación, excepto las vacaciones.

c) En ningún caso el salario integral podrá ser inferior al monto de diez (10) salarios mínimos legales mensuales, más el factor prestacional correspondiente a la empresa que no podrá ser inferior al treinta por ciento $(30 \%)$ de dicha cuantía. El monto del factor prestacional quedará exento del pago de retención en la fuente y de impuestos.

d) Este salario no estará exento de las cotizaciones a la seguridad social, ni de los aportes al SENA, ICBF, y cajas de compensación familiar, pero en el caso de estas tres últimas entidades, los aportes se disminuirán en un treinta por ciento (30\%).

e) El trabajador que desee acogerse a esta estipulación, recibirá la liquidación definitiva de su auxilio de cesantía y demás prestaciones sociales causadas hasta esa fecha, sin que por ello se entienda terminado su contrato de trabajo (L. 50/90, art. 18).

ARTICULO $40^{\circ}$-Se denomina jornal el salario estipulado por días y sueldo, el estipulado con períodos mayores (CST, art. 133).

ARTICULO $41^{\circ}$-Salvo convenio por escrito, el pago de los salarios se efectuará en el lugar en donde el trabajador presta sus servicios durante el trabajo, o inmediatamente después del cese (CST, art. 138, num. $1^{\circ}$ ).

ARTICULO $42^{\circ}-\mathrm{El}$ salario se pagará al trabajador directamente o a la persona que él autorice por escrito así:

a) El salario en dinero debe pagarse por períodos iguales y vencidos. El periodo de pago para los jornales no puede ser mayor de una semana, y para sueldos no mayor de un mes.

b) El pago del trabajo suplementario o de horas extras y el recargo por trabajo nocturno debe efectuarse junto con el salario ordinario del período en que se han causado o a más tardar con el salario del período siguiente (CST, art. 134). 


\section{CAPÍTULO XII}

\section{SERVICIO MÉDICO, MEDIDAS DE SEGURIDAD, RIESGOS PROFESIONALES, PRIMEROS AUXILIOS EN CASO DE ACCIDENTES DE TRABAJO, NORMAS SOBRE LABORES EN ORDEN A LA MAYOR HIGIENE, REGULARIDAD Y SEGURIDAD EN EL TRABAJO.}

ARTICULO $43^{\circ}$-Es obligación del empleador velar por la salud, seguridad e higiene de los trabajadores a su cargo. Igualmente, es su obligación garantizar los recursos necesarios para implementar y ejecutar actividades permanentes en medicina preventiva y del trabajo, y en higiene y seguridad industrial, de conformidad al programa de salud ocupacional, y con el objeto de velar por la protección integral del trabajador.

ARTICULO $44^{\circ}$ - Los servicios médicos que requieran los trabajadores se prestarán por el Instituto de Seguros Sociales o EPS, ARP, a través de la IPS a la cual se encuentren asignados. En caso de no afiliación estarán a cargo del empleador sin perjuicio de las acciones legales pertinentes.

ARTICULO $45^{\circ}$ - Todo trabajador dentro del mismo día en que se sienta enfermo deberá comunicarlo al administrador de la empresa, quien hará lo conducente para que sea examinado por el médico correspondiente a fin de que certifique si puede continuar o no en el trabajo y en su caso determine la incapacidad y el tratamiento a que el trabajador debe someterse.

Si éste no diere aviso dentro del término indicado o no se sometiere al examen médico que se haya ordenado, su inasistencia al trabajo se tendrá como injustificada para los efectos a que haya lugar, a menos que demuestre que estuvo en absoluta imposibilidad para dar el aviso y someterse al examen en la oportunidad debida.

ARTICULO $46^{\circ}$ - Los trabajadores deben someterse a las instrucciones y tratamiento que ordena el médico que los haya examinado, así como a los exámenes y tratamientos preventivos que para todos o algunos de ellos ordena la empresa en determinados casos. El trabajador que sin justa causa se negare a someterse a los exámenes, instrucciones o tratamientos antes indicados, perderá el derecho a la prestación en dinero por la incapacidad que sobrevenga a consecuencia de esa negativa.

ARTICULO $47^{\circ}$ - Los trabajadores deberán someterse a todas las medidas de higiene y seguridad que prescriban las autoridades del ramo en general, y en particular a las que ordene la empresa para prevención de las enfermedades y de los riesgos en el manejo de las máquinas y demás elementos de trabajo especialmente para evitar los accidentes de trabajo.

PARAGRAFO - El grave incumplimiento por parte del trabajador de las instrucciones, reglamentos y determinaciones de prevención de riesgos , adoptados en forma general o especifica, y que se encuentren dentro del programa de salud ocupacional de la respectiva empresa, que la hayan comunicado por escrito, facultan al empleador para la terminación del vínculo o relación laboral por justa causa, tanto para los trabajadores privados como los servidores públicos, previa autorización del Ministerio del Trabajo y Seguridad Social respetando el derecho de defensa (D. 1295/94, art. 91).

ARTICULO $48^{\circ}$ - En caso de accidente de trabajo, el jefe de la respectiva dependencia, o su representante, ordenará inmediatamente la prestación de los primeros auxilios, la llamada al médico si lo tuviere, o uno particular si fuere necesario, tomará todas las demás medidas que se impongan y que se consideren necesarias para reducir al mínimo las consecuencias del accidente, denunciando el mismo en los términos establecidos en el Decreto 1295 de 1994 ante la EPS y la ARP.

ARTICULO $49^{\circ}$-En caso de accidente no mortal, aun el más leve o de apariencia insignificante, el trabajador lo comunicará inmediatamente al jefe del departamento respectivo o al administrador de la empresa o empleador que haga sus veces, para que éstos procuren los primeros auxilios, prevean la asistencia médica y tratamiento oportuno y den cumplimiento a lo previsto en el artículo 220 del Código Sustantivo del Trabajo. El médico continuará el tratamiento respectivo e indicará las consecuencias del accidente y la fecha en que cese la incapacidad.

ARTICULO $50^{\circ}$-Todas las empresas y las entidades administradoras de riesgos profesionales deberán llevar estadisticas de los accidentes de trabajo y de las enfermedades profesionales para lo cual deberán en cada caso determinar la gravedad y la frecuencia de los accidentes de trabajo o de las enfermedades profesionales de conformidad con el reglamento que se expida.

El Ministerio de la Protección Social en coordinación con el Ministerio de Salud establecerán las reglas a las cuales debe sujetarse el procesamiento y remisión de esta información (D. 1295/94, art. 61).

ARTICULO $51^{\circ}$-En todo caso en lo referente a los puntos de que trata este capitulo, tanto la empresa como los trabajadores, se someterán a, las normas de riesgos profesionales del Código Sustantivo del Trabajo la Resolución 1016 de 1989 expedida por el Ministerio de la Protección Social y las demás que con tal fin se establezcan.

De la misma manera ambas partes están obligadas a sujetarse al Decreto Ley 1295 de 1994 legislación vigente sobre salud ocupacional de conformidad a los términos estipulados en los preceptos legales. 


\section{CAPÍTULO XIII}

\section{PRESCRIPCIONES DE ORDEN}

ARTICULO $52^{\circ}$ - Los trabajadores tienen como deberes los siguientes:

a) Respeto y subordinación a los superiores;

b) Respeto a sus compañeros de trabajo;

c) Procurar completa armonia e inteligencia con sus superiores y compañeros de trabajo en las relaciones personales y en la ejecución de labores;

d) Guardar buena conducta en todo sentido y obrar con espíritu de leal colaboración en el orden moral y disciplina general de la empresa;

e) Ejecutar los trabajos que le confien con honradez, buena voluntad y de la mejor manera posible;

f) Hacer las observaciones, reclamos y solicitudes a que haya lugar por conducto del respectivo superior y de manera fundada, comedida y respetuosa;

g) Ser veridico en todo caso;

h) Recibir y aceptar las órdenes, instrucciones y correcciones relacionadas con el trabajo, el orden y la conducta en general, con su verdadera intención que es en todo caso la de encaminar y perfeccionar los esfuerzos en provecho propio y de la empresa en general;

i) Observar rigurosamente las medidas y precauciones que le indique su respectivo jefe para el manejo de las máquinas o instrumentos de trabajo, y

j) Permanecer durante la jornada de trabajo en el sitio o lugar en donde debe desempeñar las labores siendo prohibido salvo orden superior, pasar al puesto de trabajo de otros compañeros.

PARAGRAFO-Los directores o trabajadores no pueden ser agentes de la autoridad pública en los establecimientos o lugares de trabajo ni intervenir en la selección del personal de la policía, ni darle órdenes, ni suministrarle alojamiento o alimentación gratuitos, ni darle dádivas (CST, art. 126, par.).

\section{CAPÍTULO XIV}

\section{ORDEN JERÁRQUICO}

ARTICULO $53^{\circ}-\mathrm{El}$ orden jerárquico de acuerdo con los cargos existentes en la empresa, es el siguiente:

Rectores

Vicerrectores

Secretario General

Jefe de Personal

Jefes de Departamentos

Decanos

Secretarios Académicos

PARAGRAFO-De los cargos mencionados, tienen facultad para imponer sanciones disciplinarias a los trabajadores de la empresa, los siguientes: Los Rectores, el Vicerrector Administrativo y el Jefe de Personal.

\section{CAPÍTULO XV}

\section{LABORES PROHIBIDAS PARA MUJERES Y MENORES}

ARTICULO $54^{\circ}-$ Queda prohibido emplear a las mujeres y menores de dieciocho años en trabajos peligrosos, insalubres o que requieran grandes esfuerzos, no podrán ser empleados en los trabajos que a continuación se enumeran, por cuanto suponen exposición severa a riesgos para su salud o integridad fisica:

a) La construcción, reconstrucción, conservación, reparación, modificación, demolición de edifício, instalaciones telegráficas o telefónicas, instalaciones eléctricas, distribución de agua u otros trabajos de construcción, así como las obras de preparación y cimentación que preceden a los trabajos antes mencionados, y

b) Trabajos que tengan que ver con sustancias tóxicas o nocivas para la salud.

c) Trabajos a temperaturas anormales o en ambientes contaminados o con insuficiente ventilación.

d) Trabajos donde se está expuesto a ruidos que sobrepasen ochenta (80) decibeles. 
e) Trabajos donde se tenga que manipular con sustancias radioactivas, pinturas luminiscentes, rayos $\mathrm{x}, \mathrm{o}$ que impliquen exposición a radiaciones ultravioletas, infrarrojas y emisiones de radiofrecuencia.

f) Todo tipo de labores que impliquen exposición a corrientes eléctricas de alto voltaje.

g) Actividades que impliquen el manejo de sustancias explosivas, inflamables o cáusticas.

h) Trabajos en máquinas esmeriladoras, afilado de herramientas, en muelas abrasivas de alta velocidad y en ocupaciones similares.

i) Trabajos y operaciones que involucren la manipulación de cargas pesadas.

PARAGRAFO - Los trabajadores menores de dieciocho (18) años y mayores de catorce (14), que cursen estudios técnicos en el Servicio Nacional de Aprendizaje o en un instituto técnico especializado reconocido por el Ministerio de Educación Nacional o en una institución del sistema nacional de bienestar familiar autorizada para el efecto por el Ministerio de la Protección Social, o que obtenga el certificado de aptitud profesional expedido por el Servicio Nacional de Aprendizaje "SENA", podrán ser empleados en aquellas operaciones, ocupaciones o procedimientos señalados en este artículo, que a juicio del Ministerio de la Protección Social, pueden ser desempeñados sin grave riesgo para la salud o la integridad fisica del menor mediante un adecuado entrenamiento y la aplicación de medidas de seguridad que garanticen plenamente la prevención de los riesgos anotados. Quedan prohibidos a los trabajadores menores de dieciocho (18) años todo trabajo que afecte su moralidad. De igual modo se prohíbe su contratación para la reproducción de escenas pornográficas, muertes violentas, apología del delito u otros semejantes (D. $2737 / 89$, arts. 245 y 246 ).

\section{CAPÍTULO XVI}

\section{OBLIGACIONES ESPECIALES PARA LA EMPRESA Y LOS TRABAJADORES}

ARTICULO 55-Son obligaciones especiales del empleador:

a) Poner a disposición de los trabajadores, salvo estipulaciones en contrario, los instrumentos adecuados y las materias primas necesarias para la realización de las labores.

b) Procurar a los trabajadores locales apropiados y elementos adecuados de protección contra accidentes y enfermedades profesionales en forma que se garanticen razonablemente la seguridad y la salud.

c) Prestar de inmediato los primeros auxilios en caso de accidentes o enfermedad, a este efecto el establecimiento mantendrá lo necesario según reglamentación de las autoridades sanitarias.

d) Pagar la remuneración pactada en las condiciones, períodos y lugares convenidos.

e) Guardar absoluto respeto a la dignidad personal del trabajador y sus creencias y sentimientos.

f) Conceder al trabajador las licencias necesarias para los fines y en los términos indicados en el capítulo VIII de este reglamento.

g) Dar al trabajador que lo solicite, a la expiración del contrato, una certificación en que conste el tiempo de servicio, indole de la labor y salario devengado, e igualmente si el trabajador lo solicita, hacerle practicar examen sanitario y darle certificación sobre el particular. Si al ingreso o durante la permanencia en el trabajo hubiere sido sometido a examen médico. Se considera que el trabajador por su culpa elude, dificulta o dilata el examen, cuando transcurridos cinco (5) días a partir de su retiro no se presenta donde el médico respectivo para las prácticas del examen, a pesar de haber recibido la orden correspondiente.

h) Pagar al trabajador los gastos razonables de venida y regreso, si para prestar su servicio lo hizo cambiar de residencia, salvo si la terminación del contrato se origina por culpa o voluntad del trabajador.

i) Si el trabajador prefiere radicarse en otro lugar, el empleador le debe costear su traslado hasta concurrencia de los gastos que demandaría su regreso al lugar donde residía anteriormente. En los gastos de traslado del trabajador se entienden comprendidos los familiares que con él convivieren.

j) Abrir y llevar al día los registros de horas extras y de trabajadores menores que ordena la ley.

k) Conceder a las trabajadoras que estén en periodo de lactancia los descansos ordenados por el artículo 238 del Código Sustantivo del Trabajo.

I) Conservar el puesto a las empleadas que estén disfrutando de los descansos remunerados, a que se refiere el numeral anterior, o por licencia de enfermedad motivada en el embarazo o parto. No producirá efecto alguno el despido que el empleador comunique a la trabajadora en tales periodos o que si acude a un preaviso, éste expire durante los descansos o licencias mencionadas.

m) Llevar un registro de inscripción de todas las personas menores de edad que emplee, con indicación de la fecha de nacimiento de las mismas.

n) Cumplir este reglamento y mantener el orden, la moralidad y el respeto a las leyes.

Además de las obligaciones especiales a cargo del empleador, éste garantizará el acceso del trabajador menor de edad a la capacitación laboral y concederá licencia no remunerada cuando la actividad escolar así lo requiera.

Será también obligación de su parte, afiliar al Instituto de Seguros Sociales a todos los trabajadores menores de edad que laboren a su servicio, lo mismo que suministrarles cada cuatro (4) meses en forma gratuita, un par de zapatos y un vestido de labor, teniendo en cuenta que la remuneración mensual sea hasta dos veces el salario mínimo vigente en la empresa (CST, art. 57).

ARTICULO $56^{\circ}$-Son obligaciones especiales del trabajador: 